\title{
Efficacy of Teachers' In-Service Training for Increasing Their Knowledge of Attention Deficit Hyperactivity Disorder in Eastern Region, Saudi Arabia
}

\author{
Tareq Melhem* \\ King Faisal University, Hofuf, Al-Ahsa, KSA \\ https://orcid.org/0000-0002-6748-1967
}

\begin{abstract}
The study aimed to assess the effectiveness of a training programme in increasing teachers' knowledge of Attention Deficit Hyperactivity Disorder (ADHD) in the Eastern Region of Saudi Arabia. The sample comprised 124 teachers from schools in the said region, and these teachers were divided into two groups: (1) experimental group with 62 teachers and (2) control group with 62 teachers. The quasiexperimental approach was employed for collecting data; the Cognitive Awareness Scale of ADHD (Melhem, 2020) was also employed. It consists of 37 items distributed into three domains, namely, general knowledge, characteristics and diagnosis and treatment. Results revealed that the effectiveness of the training programme in increasing teachers' ADHD knowledge was in favour of the experimental group. Moreover, no statistically significant differences were observed in the increase of the levels of ADHD knowledge amongst the teachers in the experimental group due to the variable of teaching experience. That is, the levels of ADHD knowledge of teachers from the experimental group are the same according to their teaching experience. In sum, the training programme significantly increased the levels of ADHD knowledge of teachers from the experimental group. Moreover, educational institutions in Saudi Arabia should include ADHD training programmes in teacher-training curricula in Saudi Arabia.
\end{abstract}

Keywords: ADHD; in-service training; teachers

\section{Introduction}

Attention Deficit Hyperactivity Disorder (ADHD) is a developmental biological disorder that is characterised by abnormal growth behaviour with deficits in the inhibition of behaviour, constant attention, resistance to distraction and selfregulation (Rief, 2016). ADHD is one of the most persistent and divisive childhood

\footnotetext{
*Corresponding author: Tareq Melhem; Email: tmelhem@kfu.edu.sa
} 
diseases and has gained considerable attention in the past thirty years from scientists, the public, and the media (Melhem, 2020; Rief, 2016). ADHD is also the most frequently diagnosed mental disorder in children of school age. The fifth edition of the Diagnostic and Statistical Manual of Mental Disorders (DSM-5), which is the official source for diagnosing ADHD, indicates that the prevalence of ADHD ranges 3\%-7\% amongst schoolchildren(American Psychiatric Association, [APA], 2013). In addition, DSM-5 emphasises that the rates of male infection with this disorder are higher than those of females for approximately two to nine times. DSM-5 also lists a number of symptoms that fall under the pattern of attention deficit, motor activity and impulsivity to prove that these symptoms must continue for at least six months with a degree that negatively affects growth level; moreover, these children have problems with paying attention continuously and diverting attention (APA, 2013).

Additionally, ADHD leads to impediments to core human life practices, such as social relations, academic success, community, professional competence, and personality; in specific, adherence to social norms, directives, and regulations. (Barkley, 2015). Despite the fact that ADHD is a mental disorder, but usually first diagnosed in the first years of early childhood, childhood stage, of adolescence (APA, 2013), the preponderance of evidence suggests that $50 \%-65 \%$ of cases of children born with this disorder continuously experience symptoms until adulthood (Pierangelo \& Giuliani, 2015). ADHD has a huge effect on society as a result of its economic implications; the pressure it imposes on teachers and parents alike; unwanted educational and professional outputs; and the damage it inflicts on the self-esteem of people suffering from this disorder. (Poznanski, Hart, \& Cramer, 2018).

Melhem (2020) reported that ADHD is prevalent at the global, regional and local levels. However, statistical survey studies, which provide the prevalence proportion of this disorder, are fewer than studies on other categories of people with special needs in each western country. Such studies are also scarce in the Arab world. Research indicates that the prevalence of the number of children affected by ADHD globally expands. In 2013, APA indicated that the prevalence ranged 3\%-5\% amongst schoolchildren (6-19 years old). Rowland et al. (2015) revealed that the statistical survey estimates of their study have reached approximately $15.5 \%$, suggesting that $15.5 \%$ of American schoolchildren in grades 1-5 have ADHD in the diverse North Carolina County. The prevalence proportion in Canada is between $5.4 \%$ and $14 \%$ amongst schoolchildren (Dilaimi, 2013). However, in Britain and other European countries, the prevalence proportion is $1.8 \%$ amongst schoolchildren (Lazarus, 2011). At the Arab level, a clear dearth is observed in accurate statistical survey studies for this purpose. Obeidat (2014) indicated that the prevalence of ADHD in Egypt is between 4\% and 20\% of schoolchildren (6-12 years old), whereas the prevalence proportion of ADHD amongst Jordanian schoolchildren ranges between 5\% and 10\%. In Saudi Arabia, the most recent studies conducted in the western part of the country show that the prevalence proportion of ADHD amongst schoolchildren (6-12 years old) is approximately 5\% (AlZaben et al., 2018). By contrast, a survey conducted in the eastern part of Saudi Arabia suggests that the prevalence proportion of ADHD amongst 1,287 students is $16.4 \%$ (Melhem, 2020). 
As a result, most teachers face a range of challenges when dealing with this group of students who suffer from ADHD which make the situation helpless for teaching in dealing with these challenges. Hence, they have no idea what method is best to use for handling them; teachers sometimes resort to shouting at students to sit down or to pay attention to the lesson; other times, teachers refer students to the school principal, a social worker or a special education teacher to deal with them (Obeidat, 2014).

However, referring students to the school principal may not work because these students often return to exhibit behaviours that disrupt the educational process in a classroom, leading to the annoyance of teachers and other students. Meanwhile, referring students to a social worker or a special education teacher may lead to a slight progress in their behaviours if such behaviours are controlled in the natural environment, that is, the classroom where they receive their education with the participation of a regular class teacher (Poznanski et al., 2018). As a result, many teachers tend to wonder about the reasons why these students have these behavioural problems and about the best methods to use to stop them or limit their effects(Melhem, 2020).

As previously indicated, teachers must have sufficient knowledge about ADHD. On one hand, teachers should know the definitions, reasons and characteristics of ADHD. On the other hand, teachers must have a practical knowledge about how to identify students; diagnosis instruments and their applications; and intervention strategies, which can contribute to controlling their behaviours. Therefore, the study aimed to show the efficacy of an in-service training program in raising the level of awareness of teachers about ADHD.

As a remedial move, different ranges of treatment interventions are tailored to assist handle the behavioural problems of individuals with ADHD. First is the interventions with medical drugs, such as, Concerta and Strattera, which are operative in reducing the essence symptoms of ADHD (Punja et al., 2016; Storebø et al., 2015). Second is the interventions classified as psychoeducational and social, both of which have been experimentally proven, including parent training and school interventions for children with ADHD (Alkahtani, 2013; Kauffman \& Landrum, 2013). Parents' training focuses on providing them with skills and strategies in implementing behaviour control and management techniques, whereas school interventions for ADHD pay attention to teachers' training to use behavioural reinforcement and punishment for managing classroom disorders. Third is the academic interventions, such as adapting instructional materials to accommodate students with ADHD (Vasko, Oddo, Meinzer, Garner \& ChronisTuscano, 2020). Fourth is the cognitive behavioural interventions, which generally emphasise the development of the self-management skills of students (Forresi et al., 2020; Ouellet, Beaulieu-Bonneau, Savard \& Morin, 2019). These findings highlight the positive effects of school interventions (from medium to large) on the improvement of the academic and behavioural outcomes of children with ADHD (Forresi et al., 2020; Prinstein, Youngstrom, Mash \& Barkley, 2019; Vasko et al., 2020). 
With regard to the discussion above, these interventions and endeavours are worthy in a valuable environment (the classroom) where students spend a long time to learn and develop adaptive skills, which, in turn, facilitate personal growth amongst social and academic students with ADHD (Poznanski et al., 2018). Therefore, teachers often play a pivotal role in performing the tasks of educational and behavioural interventions for students who suffer from ADHD in the classroom (Barkley, 2015; DuPaul \& Stoner, 2014; Shroff, Hardikar-Sawant \& Prabhudesai, 2017). Expectedly, teachers usually monitor the progress of students after treatment even if such teachers fail to implement it (Al-Moghamsi, 2018). For example, doctors heavily rely on the observations of parents and teachers to monitor the symptoms and side effects when children with ADHD begin to take prescription drugs (Alkahtani, 2013; Dilaimi, 2013). Moreover, teachers are responsible for implementing classroom management strategies, which are designed to help students with ADHD to achieve social, academic and emotional successes within the school environment (Latouche \& Gascoigne, 2019). Regrettably, results of previous studies indicated that teachers are perhaps unqualified enough to effectively provide the necessary bolster to children with ADHD due to limited training and ADHD knowledge (Alkahtani, 2013; Dilaimi, 2013; Melhem, 2020; Mohr-Jensen, Steen-Jensen, Bang-Schnack \& Thingvad, 2019; Rief, 2016; Soroa, Gorostiaga \& Balluerka, 2013).

At the same time, teachers who have undergone ADHD training have high levels of awareness and low misbeliefs about the disorder versus teachers who have not been trained (Abed, Pearson, Clarke \& Chambers, 2014; Barkley, 2015; MohrJensen et al., 2019).

One of the greatest obstacles that stand in front of teachers to become capable of meeting the special needs of these students who suffer from ADHD is the limited knowledge about it (Latouche \& Gascoigne, 2019; Melhem, 2020). Hence, teachers must know the symptoms, behaviours and diagnosis targeted by interventions; and the success of the school interventions for ADHD depends, to a large extent, on teachers' knowledge of the disorder (Alkahtani, 2013; Shroff et al., 2017). When teachers' levels of understanding about the disorder are low (in terms of its causes, effects and consequences), the attempts to design intervention programmes within the classroom fail to have significant positive impacts (Poznanski et al., 2018).

Previous studies, which employed training programmes to increase teachers' ADHD knowledge, are few. The first randomised controlled study of 49 teachers from three schools in Karachi City, Pakistan tested the effectiveness of an intensive five-day in-service training programme for two hours every day, which aimed to increase teachers' levels of ADHD knowledge; the results showed a significant increase in their levels of knowledge (Syed \& Hussein, 2010). Graeper (2011) observed a significant increase in teachers' ADHD knowledge after exposing 35 teachers to a training workshop in New York City. Similarly, Sarraf, Karahmadi, Marasy, and Azhar (2011) found an improvement in the levels of teachers' ADHD knowledge after they intervened in a two-day training programme for 67 teachers in Isfahan City, Iran. Aguiar et al. (2014) conducted a 
study on 37 teachers in Porto Alegre City, Brazil and aimed to increase teachers' ADHD knowledge through an intervention training programme for six hours for one day. The results indicated a significant increase in teachers' knowledge about ADHD. In the western region of Saudi Arabia, Obeidat (2014) aimed to increase the levels of teachers' ADHD knowledge by conducting a training programme on a sample of 80 teachers who were divided into two groups (experimental and control groups). The effectiveness of the training programme in increasing the levels of teachers' ADHD knowledge was in favour of the experimental group. Lasisi, Ani, Lasebikan, Sheikh, and Omigbodun (2017) conducted a one-day threehour training workshop in Nigeria, with a one-and-a-half hour booster session on ADHD two weeks later for 161 teachers; the training programme significantly improved the knowledge and attitudes of the teachers in the intervention group towards students with ADHD. Latouche and Gascoigne (2019) also conducted a one-day two-hour training workshop on ADHD and self-efficacy for 274 teachers in Australia. They found similar increases in ADHD knowledge, whereas the increase in self-efficacy was modest.

Note that previous research was performed for increasing teachers' ADHD knowledge, and such studies were all conducted in non-Arab environments, except for one (Obeidat, 2014), which was conducted in the Western Region of Saudi Arabia. The practical implications of these studies were conflicting between significant and slight increases in the improvement of the levels of teachers' ADHD knowledge, including their apparent lack of training and low ADHD knowledge in the Eastern Province of Saudi Arabia (Melhem, 2020).

Therefore, future studies must design effective interventions to train teachers for increasing their knowledge about ADHD and for determining how they can handle students with this disorder. That is, this research attempts to address the gap between the theoretical and practical sides by contributing in a practical way, particularly in guiding educators and educational policymakers in Saudi Arabia to adopt practical steps regarding the in-service training of teachers related to ADHD by providing a model of the training programme. The Saudi Arabia environment is in essential need of such programmes in light of the infrequency of experimental studies in the Arab region addressing the same problem as previously mentioned. Moreover, the research proposes the inclusion of preservice training in the curricula of educational institutions by adding courses, seminars and training workshops related to ADHD during university studies.

\subsection{Purpose of the Study and Research Questions}

The study seeks to determine the efficacy of an in-service training programme to improve the level of knowledge of school teachers about ADHD. To the best of the researcher's knowledge, no study has been conducted in the Eastern Province of Saudi Arabia for the same purpose. Hence, the following research questions are put forward:

Research Question 1: Does the in-service training programme on ADHD have a significant main effect on increasing teachers' ADHD knowledge when the effect of the pre-test results in the ADHD knowledge scale is controlled? 
Research Question 2: Based on the post-test results in the ADHD knowledge scale, are statistically significant differences present in increasing teachers' ADHD knowledge due to participants' teaching experience when the effect of the pre-test results in the ADHD knowledge scale is controlled?

\section{Research Method and Procedures}

\subsection{Design}

The research design is an overall strategy or an outline on how to conduct research (Mills \& Gay, 2019). The quasi-experimental design uses the pre-test-post-test control group design. Leavy (2017) emphasised that experimental studies offer the best proof on how something affects something else, and the best tests are doubleblind, randomised control experiments.

This study employs the quasi-experimental research design to examine the research problem, the objectives of the study and the research questions for obtaining an improved insight into the issues at hand. These considerations emphasise the importance of using the quasi-experimental research design to fulfil the objectives of the study and to ponder on the research questions, which can be key to the solutions. This advantage warrants the use of this research design in this study.

The main aim is to increase the ADHD knowledge of teachers through an inservice training programme. An independent variable, which is the training programme, and one dependent variable, namely, the levels of teachers' ADHD knowledge are also utilised, as illustrated in Figure (1) below:

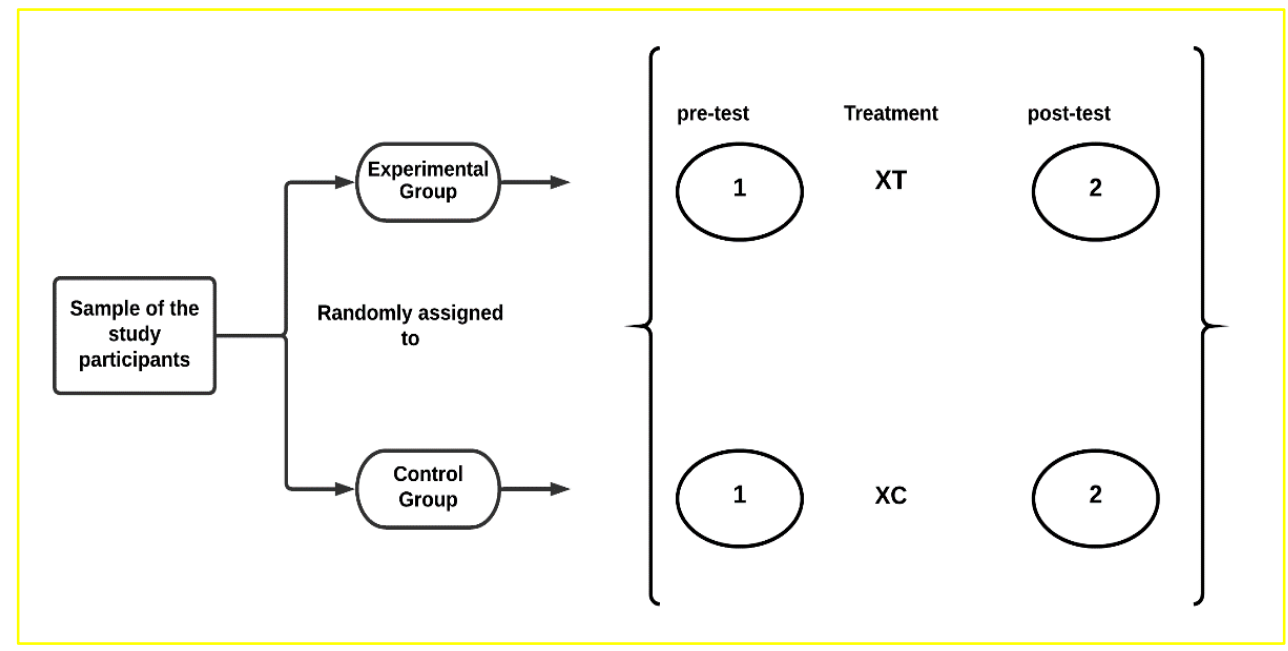

Figure 1: Study design

Symbol (O1) indicates that a pre-test is conducted. (XT) refers to the teachers in the experimental group who are exposed to the training programme on ADHD, whereas $(\mathrm{XC})$ refers to the teachers in the control group who are not. A post-test is conducted, as denoted by $(\mathrm{O} 2)$. 


\subsection{Study Population and Sample}

The study population consists of 450 teachers who enrolled in the summer training programmes at King Faisal University during the academic year 20182019 from public education schools in Eastern Province, Saudi Arabia. Amongst them, 124 volunteer teachers are purposely selected. These teachers are divided into two equivalent groups: (1) the experimental group subjected to intervention, with 62 teachers and (2) the control group not subjected to intervention, comprising 62 teachers. The study individuals are distributed according to the variable of teaching experience, as presented in Table 1 below:

Table 1. Distribution of study individuals according to the variable of teaching experience

\begin{tabular}{|c|c|c|c|c|c|}
\hline Variable & Category & $\begin{array}{l}\text { Experimental } \\
\text { Group }\end{array}$ & Control Group & Frequency & Percentage \\
\hline \multirow{4}{*}{$\begin{array}{l}\text { Teaching } \\
\text { experience }\end{array}$} & $\begin{array}{l}\text { One to five } \\
\text { years }\end{array}$ & 24 & 24 & 48 & $38.70 \%$ \\
\hline & $\begin{array}{lll}\text { five to } & 10 \\
\text { years } & \end{array}$ & 23 & 23 & 46 & $37.01 \%$ \\
\hline & $\begin{array}{ll}\text { Above } & 10 \\
\text { years } & \end{array}$ & 15 & 15 & 30 & $24.19 \%$ \\
\hline & Total & 62 & 62 & 124 & $100 \%$ \\
\hline
\end{tabular}

One-way ANCOVA is used to adjust the differences between the means of the pre-test scores of teachers from the experimental and control groups. Conducting a parity analysis on the pre-test of the two groups is necessary to prevent the posttest results from being affected. Note that one-way ANCOVA solves this possible problem in case differences are observed during the pre-test between the experimental and control groups.

\subsection{Study Instrument}

A scale, which was developed by Melhem (2020), is used to measure the levels of teachers' ADHD knowledge. This scale is an adaptation of a 37-item scale previously developed by Sciutto, Terjesen, and Frank (2000) and is directed towards teachers' ADHD knowledge. However, a scale that measures teachers' ADHD knowledge is prepared for educational situations normally faced by teachers in schools. Melhem's (2020) scale is translated into Arabic and developed on the basis of the scale of Sciutto et al. (2000). He also benefited from other scales, such as that of Jerome, Gordon and Hustler (1994) because he included studies on teachers' ADHD knowledge (Abed et al., 2014; Al-Moghamsi, 2018; Alkahtani, 2013; Anderson, Watt, Noble \& Shanley, 2012; Dilaimi, 2013; Yarde-Leavett, 2018).

The scale has 37 items distributed over the positive and negative on three domains, namely, general knowledge (15 items), characteristics and diagnosis (nine items) and treatment (13 items). The scale also has acceptable validity and reliability indications for the purposes of its use in the study. The value of the reliability coefficient for the total scale is 0.891 ; the values of the reliability coefficients for the first (general knowledge), second (characteristics and diagnosis) and third (treatment) domains are 0.840, 0.780 and 0.796 , respectively. 


\subsection{Intervention}

The training programme was developed and built on the basis of the theoretical literature and previous studies related to ADHD (Aguiar et al., 2014; Alkhateeb \& Alhadidi, 2019; Barkley, 2015; Corkum, Elik, Blotnicky-Gallant, McGonnell \& McGrath, 2019; DuPaul \& Stoner, 2014; Lasisi et al., 2017; Latouche \& Gascoigne, 2019; Melhem, 2020; Obeidat, 2014; Poznanski et al., 2018; Prinstein et al., 2019; Rief, 2016; Vasko et al., 2020). The aim of the training programme was to increase the levels of teachers' ADHD knowledge. It consisted of 10 training sessions for five days, two hours per session. The training programme was delivered in PowerPoint format. There was a time for questions and discussions throughout the training session and at the end of it. The following subjects were covered by the training programme: the importance of attention in the educational process; factors affecting attention; misconceptions about ADHD; and the historical development of the disorder, its definition and its prevalence rate. The causes of the disorder (genetic, neurological and environmental), its patterns and characteristics were also discussed. In addition, the programme covered methods of evaluation and diagnosis of the disorder; for example, the most prominent therapeutic interventions (behavioural, cognitive behavioural and medical) used for children with ADHD, classroom management derived from classroom settings for children with ADHD, tools that assist teachers in implementing ADHD teaching strategies, models that provide strategies for classroom management and video clips to facilitate learning. The researcher (Assistant Professor of Special Education) conducted the training programme.

\subsection{Procedure}

The necessary ethical approves were acquired from Ethical Review Committee at The King Faisal University. The online training programme was announced as part of the summer programmes offered by the Saudi Ministry of Education in cooperation with the School of Education at King Faisal University for the academic year 2018-2019. The teachers registered for the online training programme. The pre-test of the ADHD knowledge scale was conducted amongst the participants before the intervention (training programme), and the teachers were divided into experimental and control groups. The intervention was performed on the experimental group only by implementing the training programme within approximately one week (five days, two training sessions per day). After the intervention (training programme), the post-test of the ADHD knowledge scale was conducted amongst the two groups (experimental and control).

\subsection{Data Analysis}

One-way ANCOVA was used to adjust the differences between the means of the pre-test scores of the teachers from the experimental and control groups; the significance of the differences between the means of teachers' post-test scores was also determined to verify whether the in-service training programme increased their ADHD knowledge from the pre-intervention phase to the post-intervention phase (effectiveness of the training programme). Eta squared (n2), which was obtained by following Cohen's instructions, was used to identify the effect size of the in-service training programme in increasing teachers' ADHD knowledge; note 
that ' $0.01=$ small effect, $0.06=$ moderate effect and $0.14=$ large effect' $($ Cohen, 2013). All assumptions were met for all statistical analyses.

\section{Results}

\subsection{Results of Research Question 1}

To address the first question, the means and standard deviations (SDs) of the preand post-test scores of teachers (from both groups) on the ADHD knowledge scale were calculated. The results are presented in Table 2.

Table 2. Means and SDs of the pre- and post-test scores of teachers on the ADHD knowledge scale.

\begin{tabular}{|l|l|c|c|c|c|c|}
\hline \multicolumn{1}{|c|}{ Scale Domain } & \multicolumn{1}{|c|}{ Group } & \multirow{2}{*}{$N$} & \multicolumn{2}{c|}{ Pre-test } & \multicolumn{2}{c|}{ Post-test } \\
\cline { 4 - 7 } & & & Mean & SD & Mean & SD \\
\hline \multirow{3}{*}{ General knowledge } & Experimental & 62 & 5.66 & 2.46 & 10.32 & 2.53 \\
\cline { 2 - 7 } & Control & 62 & 5.85 & 2.62 & 6.69 & 2.48 \\
\hline $\begin{array}{l}\text { Characteristics and } \\
\text { diagnosis }\end{array}$ & Experimental & 62 & 4.73 & 1.66 & 7.45 & 1.29 \\
\cline { 2 - 7 } & Control & 62 & 5.15 & 1.64 & 5.74 & 1.57 \\
\hline Treatment & Experimental & 62 & 5.08 & 2.34 & 10.05 & 1.66 \\
\cline { 2 - 7 } & Control & 62 & 5.03 & 1.86 & 6.60 & 2.31 \\
\hline Total test & Experimental & 62 & 15.47 & 5.50 & 27.82 & 4.50 \\
\cline { 2 - 7 } & Control & 62 & 16.03 & 4.83 & 19.03 & 5.15 \\
\hline
\end{tabular}

Table 2 shows that virtual differences were observed in the overall mean pre-test scores on the ADHD knowledge scale between teachers in the experimental and control groups. Such differences were also found in each of the three domains. These differences were statistically adjusted using one-way ANCOVA. Table 2 also presents the virtual differences in the overall mean post-test scores on the ADHD knowledge scale and in its three domains between teachers in the experimental and control groups. One-way ANCOVA was used to determine if the differences in the overall mean post-test scores of teachers from the experimental and control groups are statistically significant $(p \leq 0.05)$. ANCOVA was also employed to statistically isolate the differences between the two groups of the pre-test on the ADHD knowledge of teachers. Table 3 provides the results.

Table 3. Results of ANCOVA for the overall post-test scores of teachers on the ADHD knowledge scale.

\begin{tabular}{|l|l|c|c|c|c|c|c|}
\hline Scale Domain & Source & $\begin{array}{c}\text { Sum of } \\
\text { Squares }\end{array}$ & df & $\begin{array}{c}\text { Mean } \\
\text { Square }\end{array}$ & $\begin{array}{c}\text { Calculated } \\
\text { Values }(\boldsymbol{F})\end{array}$ & Sig. & $\begin{array}{c}\text { Partia } \\
\mathbf{1 ~ \eta 2}\end{array}$ \\
\hline \multirow{4}{*}{$\begin{array}{l}\text { General } \\
\text { knowledge }\end{array}$} & Pre-test & 0.249 & 1 & 0.249 & 0.039 & & \\
\cline { 2 - 9 } & Group & 408.439 & 1 & 408.439 & 64.478 & $0.000^{*}$ & 0.348 \\
\cline { 2 - 9 } & Error & 766.477 & 121 & 6.335 & & & \\
\cline { 2 - 9 } & $\begin{array}{l}\text { Corrected } \\
\text { total }\end{array}$ & 1174.992 & 123 & & & & \\
\hline \multirow{2}{*}{$\begin{array}{c}\text { Characteristic } \\
\text { s and agnosis }\end{array}$} & Pre-test & 1.205 & 1 & 1.205 & 0.583 & $0.000^{*}$ & 0.257 \\
\cline { 2 - 9 } & Group & 86.534 & 1 & 86.534 & 41.879 & & \\
\cline { 2 - 9 } & Error & 250.021 & 121 & 2.066 & & & \\
\cline { 2 - 8 } & $\begin{array}{l}\text { Corrected } \\
\text { total }\end{array}$ & 341.839 & 123 & & & & \\
\hline
\end{tabular}




\begin{tabular}{|l|l|c|c|c|c|c|c|}
\hline Scale Domain & Source & $\begin{array}{c}\text { Sum of } \\
\text { Squares }\end{array}$ & $\mathbf{d f}$ & $\begin{array}{c}\text { Mean } \\
\text { Square }\end{array}$ & $\begin{array}{c}\text { Calculated } \\
\text { Values (F) }\end{array}$ & $\begin{array}{c}\text { Sig. } \\
\text { Partia } \\
\mathbf{1} \eta \mathbf{2}\end{array}$ \\
\hline \multirow{5}{*}{ Treatment } & Pre-test & 5.056 & 1 & 5.056 & 1.252 & $0.000^{*}$ & 0.430 \\
\cline { 2 - 8 } & Group & 368.278 & 1 & 368.278 & 91.181 & & \\
\cline { 2 - 9 } & Error & 488.719 & 121 & 4.039 & & & \\
\cline { 2 - 8 } & $\begin{array}{l}\text { Corrected } \\
\text { total }\end{array}$ & 863.097 & 123 & & & & \\
\hline \multirow{5}{*}{ Total test } & Pre-test & 4.865 & 1 & 4.865 & 0.207 & $0.000^{*}$ & 0.458 \\
\cline { 2 - 9 } & Group & 2399.993 & 1 & 2399.993 & 102.105 & & \\
\cline { 2 - 8 } & Error & 2844.119 & 121 & 23.505 & & & \\
\cline { 2 - 8 } & $\begin{array}{l}\text { Corrected } \\
\text { total }\end{array}$ & 5244.347 & 123 & & & & \\
\hline
\end{tabular}

* Statically significant at the .05 level.

Table 3 presents the statistically significant differences between the mean scores of the control and experimental groups on the post-test of the ADHD knowledge scale and its three domains. The $F$ values for the differences between the two groups ranged between 41.879 and 102.105; both values are statistically significant at $p \leq 0.05$.

Therefore, the in-service training programme on ADHD has a statistically significant difference in increasing the ADHD knowledge of teachers, in favour of those subjected to such a programme. $\eta 2$, where the total $\eta 2$ on the ADHD knowledge scale reaches (0.458), with a large effect size (1.14), was used to identify the effect size of the in-service training programme on ADHD (Cohen, 2013). Accordingly, $45.8 \%$ of the variances in the levels of ADHD knowledge of teachers from the experimental and control groups were due to the in-service training programme conducted in this study.

The $\eta 2$ for the three domains of the scale - general knowledge, characteristics and diagnosis and treatment-were $0.348,0.257$ and 0.430 , respectively. These results indicated the effectiveness of the in-service training programme in increasing the levels of teachers' ADHD knowledge amongst school teachers.

To determine the values of the differences in the overall mean post-test scores of teachers from the experimental and control groups on the ADHD knowledge scale and its three domains, the estimated marginal means of the post-test scores were calculated for statistically removing the effect of the covariate. As a result, the total adjusted mean of the post-test scores of teachers who received the in-service training programme on ADHD was 27.83, whereas that of teachers who did not receive any training was 19.02 (Table 4 ).

Table 4. Estimate marginal means of the post-test results of ADHD knowledge for teachers who received the in-service training programme on ADHD and for those who did not receive any training.

\begin{tabular}{|l|l|c|c|}
\hline \multicolumn{1}{|c|}{ Test Domain } & \multicolumn{1}{|c|}{ Group } & Adjusted Mean & Standard Error \\
\hline \multirow{2}{*}{ General knowledge } & Experimental & 10.32 & 0.32 \\
\cline { 2 - 4 } & Control & 6.69 & 0.32 \\
\hline \multirow{2}{*}{$\begin{array}{l}\text { Characteristics and } \\
\text { diagnosis }\end{array}$} & Experimental & 7.44 & 0.18 \\
\cline { 2 - 4 } & Control & 5.76 & 0.18 \\
\hline
\end{tabular}




\begin{tabular}{|l|l|c|c|}
\hline \multicolumn{1}{|c|}{ Test Domain } & \multicolumn{1}{c|}{ Group } & Adjusted Mean & Standard Error \\
\hline \multirow{2}{*}{ Treatment } & Experimental & 10.05 & 0.26 \\
\cline { 2 - 4 } & Control & 6.60 & 0.26 \\
\hline \multirow{2}{*}{ Total test } & Experimental & 27.83 & 0.62 \\
\cline { 2 - 4 } & Control & 19.02 & 0.62 \\
\hline
\end{tabular}

In Table 4, the results of the estimated marginal means of teachers' post-test scores on the three domains of the ADHD knowledge scale are also presented. After the pre-test effect was isolated, the adjusted means of the post-test scores of teachers who received the in-service training programme on ADHD were 10.32, 7.44 and 10.05, whereas those of teachers who did not receive any training were 6.69, 5.76 and 6.60. It comes safe to say that the results revealed that the difference was in favour of the teachers who received the in-service training programme on ADHD, whose adjusted means were relatively higher than teachers who did not receive any training. That is, the in-service training programme on ADHD has a more positive effect on the increase of teachers' ADHD knowledge than on that of teachers without training.

\subsection{Results of Research Question 2}

To answer the second question, the means and SDs of the pre- and post-test scores of teachers from the experimental group for the ADHD knowledge scale and its three domains were calculated according to the teaching experience variable (one to five years, five to 10 years and more than 10 years). This calculation determines the significance of the differences between the mean scores of teachers belonging to the experimental group. The results are shown in Table 5.

Table 5. Means and SDs of the pre- and post-test scores of teachers on the ADHD knowledge scale due to the teaching experience variable

\begin{tabular}{|c|c|c|c|c|c|c|}
\hline \multirow{2}{*}{ Scale Domain } & \multirow{2}{*}{$\begin{array}{l}\text { Teaching } \\
\text { Experience } \\
\text { Variable }\end{array}$} & \multirow{2}{*}{$N$} & \multicolumn{2}{|c|}{ Pre-test } & \multicolumn{2}{|c|}{ Post-test } \\
\hline & & & Mean & SD & Mean & SD \\
\hline \multirow{3}{*}{$\begin{array}{l}\text { General } \\
\text { knowledge }\end{array}$} & $\begin{array}{l}\text { One to five } \\
\text { years }\end{array}$ & 24 & 5.63 & 2.14 & 9.92 & 3.18 \\
\hline & $\begin{array}{l}\text { Five to } 10 \\
\text { years }\end{array}$ & 23 & 5.04 & 2.87 & 11.13 & 2.07 \\
\hline & $\begin{array}{l}\text { More than } \\
10 \text { years }\end{array}$ & 15 & 6.67 & 2.06 & 9.73 & 1.71 \\
\hline \multirow{3}{*}{$\begin{array}{l}\text { Characteristics } \\
\text { and diagnosis }\end{array}$} & $\begin{array}{l}\text { One to five } \\
\text { years }\end{array}$ & 24 & 4.92 & 1.32 & 7.50 & 1.22 \\
\hline & $\begin{array}{l}\text { Five to } 10 \\
\text { years }\end{array}$ & 23 & 4.09 & 1.98 & 7.52 & 1.12 \\
\hline & $\begin{array}{l}\text { More than } \\
10 \text { years }\end{array}$ & 15 & 5.40 & 1.35 & 7.27 & 1.67 \\
\hline \multirow{3}{*}{ Treatment } & $\begin{array}{l}\text { One to five } \\
\text { years }\end{array}$ & 24 & 5.54 & 2.27 & 10.17 & 1.74 \\
\hline & $\begin{array}{l}\text { Five to } 10 \\
\text { years }\end{array}$ & 23 & 4.43 & 2.59 & 10.30 & 1.55 \\
\hline & $\begin{array}{l}\text { More than } \\
10 \text { years }\end{array}$ & 15 & 5.33 & 1.95 & 9.47 & 1.69 \\
\hline
\end{tabular}




\begin{tabular}{|l|l|c|c|c|c|c|}
\hline \multirow{3}{*}{ Scale Domain } & $\begin{array}{l}\text { Teaching } \\
\text { Experience } \\
\text { Variable }\end{array}$ & $N$ & \multicolumn{2}{|c|}{ Pre-test } & \multicolumn{2}{|c|}{ Post-test } \\
\cline { 4 - 7 } Total scale & $\begin{array}{l}\text { One to five } \\
\text { years }\end{array}$ & 24 & 16.08 & 4.54 & 27.58 & 5.36 \\
\cline { 2 - 7 } & $\begin{array}{l}\text { Five to 10 } \\
\text { years }\end{array}$ & 23 & 13.57 & 6.63 & 28.96 & 3.86 \\
\cline { 2 - 7 } & $\begin{array}{l}\text { More than } \\
10 \text { years }\end{array}$ & 15 & 17.40 & 4.29 & 26.47 & 3.64 \\
\hline
\end{tabular}

Table 5 presents the virtual differences between the mean pre-test scores of teachers in the experimental group on the ADHD knowledge scale and its three domains due to the teaching experience variable. These differences were adjusted statistically by using one-way ANCOVA. Moreover, Table 5 indicates the virtual differences in the mean post-test scores between teachers in the experimental group on the ADHD knowledge scale and its three domains due to the teaching experience variable. One-way ANCOVA was also used to determine if such differences are statistically significant $p \leq 0.05$ and to statistically isolate the differences between teachers in the experimental group in the pre-test of scale. The results are shown in Table 6.

Table 6. Results of the one-way ANCOVA test of teachers' post-test scores according to the teaching experience variable on the ADHD knowledge scale

\begin{tabular}{|c|c|c|c|c|c|c|}
\hline Scale Domain & Source & $\begin{array}{l}\text { Sum of } \\
\text { Squares }\end{array}$ & df & $\begin{array}{l}\text { Mean } \\
\text { Square }\end{array}$ & $F$ & Sig. \\
\hline \multirow{4}{*}{$\begin{array}{l}\text { General } \\
\text { knowledge }\end{array}$} & Pre-test & 22.278 & 1 & 22.278 & 3.744 & \\
\hline & $\begin{array}{l}\text { Teaching } \\
\text { experience }\end{array}$ & 34.033 & 2 & 17.017 & 2.860 & 0.065 \\
\hline & Error & 345.097 & 58 & 5.950 & & \\
\hline & Corrected total & 391.548 & 61 & & & \\
\hline \multirow{4}{*}{$\begin{array}{l}\text { Characteristics } \\
\text { and diagnosis }\end{array}$} & Pre-test & 2.551 & 1 & 2.551 & 1.508 & \\
\hline & $\begin{array}{l}\text { Teaching } \\
\text { experience }\end{array}$ & 0.273 & 2 & 0.137 & 0.081 & 0.923 \\
\hline & Error & 98.121 & 58 & 1.692 & & \\
\hline & Corrected total & 101.355 & 61 & & & \\
\hline \multirow[t]{4}{*}{ Treatment } & Pre-test & 5.389 & 1 & 5.389 & 1.996 & \\
\hline & $\begin{array}{l}\text { Teaching } \\
\text { experience }\end{array}$ & 8.269 & 2 & 4.134 & 1.532 & 0.225 \\
\hline & Error & 156.548 & 58 & 2.699 & & \\
\hline & Corrected total & 168.855 & 61 & & & \\
\hline \multirow[t]{4}{*}{ Total scale } & Pre-test & 49.078 & 1 & 49.078 & 2.529 & \\
\hline & $\begin{array}{l}\text { Teaching } \\
\text { experience }\end{array}$ & 86.755 & 2 & 43.378 & 2.235 & 0.116 \\
\hline & Error & 1125.445 & 58 & 19.404 & & \\
\hline & Corrected total & 1233.048 & 61 & & & \\
\hline
\end{tabular}

As presented in Table 6, no statistically significant differences existed between the mean post-test scores of teachers from the experimental group on the ADHD knowledge scale due to the teaching experience variable (one to five years, five to years and more than 10 years). The $F$ values for the differences between the three categories of the teaching experience variable ranged between 0.081 and 2.860, 
which were not statistically significant at $p \leq 0.05$. That is, the improvement in the levels of teachers' ADHD knowledge in the experimental group does not differ according to their teaching experience. This result suggests that undergoing the training programme affects the increase of the levels of teachers' ADHD knowledge with the same degree regardless of the teaching experience.

\section{Discussion}

The study seeks to assess the efficacy of an in-service training programme to increase the level of knowledge of school teachers about ADHD. As expected, the training programme increased teachers' ADHD knowledge, and no statistically significant effect of the teaching experience variable was observed on the increase of teachers' ADHD knowledge levels. Based on the total score and the three subdomains of the ADHD knowledge scale, the training programme significantly improved the levels of ADHD knowledge of teachers from the experimental group from low to high. By contrast, those of teachers belonging to the control group remained low. Consequently, the improvement in the total post-test scores of teachers in the experimental group was higher than that in the total post-test scores of teachers belonging to the control group, reaching 0.458 (according to $\eta 2$ ), which is a large effect size. This result indicated $45.8 \%$ of the variance in the levels of ADHD knowledge amongst teachers from the experimental and control groups due to the training programme conducted in the study. The $\eta 2$ of each domain was $0.348,0.257$ and 0.430 , suggesting the effectiveness of the in-service training programme in increasing the levels of ADHD knowledge amongst teachers. The results described in this study are consistent with those in several previous investigations (Aguiar et al., 2014; Bradshaw \& Kamal, 2013; Graeper, 2011; Lasisi et al., 2017; Latouche \& Gascoigne, 2019; Obeidat, 2014; Sarraf et al., 2011; Syed \& Hussein, 2010), suggesting the effectiveness of in-service training programmes in increasing the levels of teachers' ADHD knowledge.

Such an increase might be due to the programme's reliance on various educational strategies and methods, such as dialogue, discussion and participatory learning. Thus, the trainees took an active role, apart from being recipients of information. The use of worksheets before the training session also helped in identifying the topics to be discussed and in determining whether information was accurate. Teachers then directed the procedures of the training session for correcting the misconceptions amongst the trainees. The researcher evaluated what the trainees gained during the training session by submitting worksheets at the end of each session to determine the extent of their acquisition of the information provided. Subsequently, corrective feedback on their responses was provided to the trainees. The effectiveness of a training programme in increasing knowledge about ADHD might be related to the use of modern educational technologies, such as PowerPoint presentations and interactive video clips, both of which helped in attracting the attention of the trainees, thereby facilitating the delivery and clarification of information to them. Moreover, teachers' desire to obtain further information about ADHD might have played an important role in improving their levels of ADHD knowledge, increasing their motivation to listen and participate in the training programme session. The training programme provided the trainees with practical solutions, which are applicable in the 
classroom; these solutions encouraged them to focus on the content provided during the training programme days.

The strengthening and expansion of the limited research were also highlighted; such research has been investigating the effectiveness of the training programme to increase the ADHD knowledge of teachers. To the researcher's knowledge, this study is the first to investigate the impact of a specialised training programme for teachers on handling children with ADHD in the Eastern Province of Saudi Arabia. Methodologically, certain limitations of previous studies were addressed in the current research by involving a large sample and using a reliable measure in terms of the indications of validity and reliability; doing so made the programme coordination easily applicable and repeatable. A control group was also formed for comparison. In sum, the training programme was effective in increasing teachers' ADHD knowledge. However, no statistically significant effect of the teaching experience variable was observed on the results. That is, the in-service training programme was effective in increasing the levels of ADHD knowledge of all teachers from the experimental group despite the different years of teaching experience amongst them.

\section{Limitations and Further Research}

Despite these favourable results, a set of determinants was considered. Firstly, teachers who are interested in the summer training programmes facilitated by the Ministry of Education in the Eastern Region were involved; particularly the programmes offered in the academic year 2018-2019. Volunteers may find such an involvement bias and therefore restrict the generalisation of findings to teachers who are more likely than others to involve in programmes of this kind. (Corkum et al., 2019). Secondly, only 'teaching experience' was the considered study variable. Future studies must pay attention to other variables, such as gender, specialisation and academic qualification. Thirdly, despite the effectiveness of the training programme, the degree of ADHD knowledge retention was unverified after the post-application of the study scale was completed. This verification should be included in future research. Lastly, a difference was found in the mean years of experience amongst the teachers. However, the study failed to observe an effect of this difference on the increase of teachers' ADHD knowledge. Nevertheless, previous studies found that the teaching experience variable has a positive relationship with knowledge (Abed et al., 2014; Al-Moghamsi, 2018; Alkahtani, 2013; Anderson et al., 2012; Dilaimi, 2013; Melhem, 2020; Pearson, Clarke \& Chambers, 2014; Shroff et al., 2017; YardeLeavett, 2018).

\section{Conclusion and Recommendations}

The conclusion has several beneficial effects on the practical field, despite the abovementioned limitations. Intensive in-service professional development programmes could be used to greatly increase the knowledge of ADHD teachers which provides real support to resolve this proven gap in teacher training. (Bradshaw \& Kamal, 2013; Gehrman, 2013; Lasisi et al., 2017; Latouche \& Gascoigne, 2019; Obeidat, 2014). Moreover, all teachers in the sample have not undergone training and have low levels of knowledge before applying to the 
training programme. Therefore, professional development programmes must be conducted during or before service to increase teachers' ADHD knowledge, similar to the programme developed in this study. Although this intensive inservice training programme cannot substitute for the integrated and general training in student behaviour management and for the strategies used in the classroom, It can be an effective first step to help teachers better recognize and reinforce the behaviours of children with ADHD by using evidence-based approaches.

The research recommendations are arranged according to the results, as follows: Firstly, future studies may assess the impact of the training programme on other variables. Secondly, educational institutions should develop the positive attitudes of teachers towards individuals with ADHD by preparing an integrated system of procedures. Thirdly, the training programme can apply to different samples, such as teachers' pre-service. Fourthly, the actual training needs of school teachers in the field of special education can be investigated. Lastly, the 124 teachers involved in the study suggest a great need for training programmes within the educational field. Although the years of teaching experience have no effect on the levels of ADHD knowledge, an intensive in-service training programme is highly effective in increasing such knowledge; hence addressing the established gap in teacher training that prevents teachers from meeting the needs of students with ADHD.

\section{References}

Abed, M., Pearson, S., Clarke, P., \& Chambers, M. (2014). Saudi Arabian Teachers' Knowledge and Beliefs about ADHD. Journal of the International Association of Special Education, 15(1), 8.

Aguiar, A. P., Kieling, R. R., Costa, A. C., Chardosim, N., Dorneles, B. V., Almeida, M. R., ... Rohde, L. A. (2014). Increasing teachers' knowledge about ADHD and learning disorders: An investigation on the role of a psychoeducational intervention. Journal of Attention Disorders, 18(8), 691-698.

Al-Moghamsi, E. a. Y. A. (2018). Elementary school teachers' knowledge of attention deficit/hyperactivity disorder. Journal of Family Medicine and Primary Care, 7(5), 907. doi:10.4103/jfmpc.jfmpc_183_18

Alkahtani, K. D. (2013). Teachers' knowledge and misconceptions of attention $\begin{array}{llll}\text { deficit/hyperactivity } \quad \text { disorder. } & \text { Psychology, } & 4(12), & \end{array}$ doi:10.4236/psych.2013.412139

Alkhateeb, J. M., \& Alhadidi, M. S. (2019). ADHD Research in Arab Countries: A Systematic Review of Literature. Journal of attention disorders, 23(13), 1531-1545. doi:10.1177/1087054715623047

AlZaben, F. N., Sehlo, M. G., Alghamdi, W. A., Tayeb, H. O., Khalifa, D. A., Mira, A. T., . . . Koenig, H. G. (2018). Prevalence of attention deficit hyperactivity disorder and comorbid psychiatric and behavioral problems among primary school students in western Saudi Arabia. Saudi medical journal, 39(1), 52.

American Psychiatric Association. (2013). Diagnostic and statistical manual of mental disorders (DSM-5®): American Psychiatric Pub.

Anderson, D. L., Watt, S. E., Noble, W., \& Shanley, D. C. (2012). Knowledge of attention deficit hyperactivity disorder (ADHD) and attitudes toward teaching children with ADHD: The role of teaching experience. Psychology in the Schools, 49(6), 511525. doi:10.1002/pits. 21617 
Barkley, R. A. (2015). Attention-deficit hyperactivity disorder: A handbook for diagnosis and treatment (4 ed.): Guilford Publications.

Bradshaw, L., \& Kamal, M. J. N. (2013). Teacher knowledge, training and acceptance of students with ADHD in their classrooms: Qatar case study. Near and Middle Eastern Journal of Research in Education, 2013(1), 5. doi:10.5339/nmejre.2013.5

Cohen, J. (2013). Statistical power analysis for the behavioral sciences: Academic press.

Corkum, P., Elik, N., Blotnicky-Gallant, P. A., McGonnell, M., \& McGrath, P. J. J. o. a. d. (2019). Web-based intervention for teachers of elementary students with ADHD: $\begin{array}{llll}\text { Randomized } & \text { controlled } & \text { 23(3), }\end{array}$ doi:doi.org/10.1177/1087054715603198

Dilaimi, A. (2013). New Zealand primary school teachers' knowledge and perceptions of attentiondeficit/hyperactivity disorder (ADHD). (Master's Thesis), Massey University, Albany, New Zealand. Retrieved from http://hdl.handle.net/10179/5127

DuPaul, G. J., \& Stoner, G. (2014). ADHD in the schools: Assessment and intervention strategies (3rd ed.): Guilford Publications.

Forresi, B., Soncini, F., Bottosso, E., Di Pietro, E., Scarpini, G., Scaini, S., . . Righi, E. (2020). Post-traumatic stress disorder, emotional and behavioral difficulties in children and adolescents 2 years after the 2012 earthquake in Italy: an epidemiological cross-sectional study. European Child \& Adolescent Psychiatry, 29(2), 227-238. doi:10.1007/s00787-019-01370-0

Gehrman, D. R. (2013). General Education Teachers' Perceptions of Students with ADHD and Professional Development. Citeseer,

Graeper, K. D. (2011). ADHD in-service training: An examination of knowledge, efficacy, stress, teaching behavior, and irrational thoughts. (Doctor's thesis), St. John's University, New York, ProQuest Dissertations Publishing. Retrieved from https://searchproquest-

com.sdl.idm.oclc.org/docview/851314817/C8E5E0F3DC4A45DFPQ/1?accounti $\mathrm{d}=142908$ (3441881.)

Jerome, L., Gordon, M., \& Hustler, P. (1994). A comparison of American and Canadian teachers' knowledge and attitudes towards attention deficit hyperactivity disorder (ADHD). The Canadian Journal of Psychiatry, 39(9), 563-567. doi:10.1177/070674379403900909

Kauffman, J. M., \& Landrum, T. J. (2013). Cases in Emotional and Behavioral Disorders of Children and Youth: Pearson Education.

Lasisi, D., Ani, C., Lasebikan, V., Sheikh, L., \& Omigbodun, O. (2017). Effect of attentiondeficit-hyperactivity-disorder training program on the knowledge and attitudes of primary school teachers in Kaduna, North West Nigeria. Child and adolescent psychiatry and mental health, 11(1), 15. doi:10.1186/s13034-017-0153-8

Latouche, A. P., \& Gascoigne, M. (2019). In-service training for increasing teachers' ADHD knowledge and self-efficacy. Journal of attention disorders, 23(3), 270-281. doi:10.1177/1087054717707045

Lazarus, K. J. (2011). The knowledge and perceptions of Attention Deficit Hyperactivity Disorder held by foundation phase educators in a Township in Gauteng.

Leavy, P. (2017). Research design: Quantitative, qualitative, mixed methods, arts-based, and community-based participatory research approaches. New York, NY: Guilford Publications.

Melhem, T. Y. (2020). Level of Awareness among Teachers about ADHD: A field study in the Eastern Province of Saudi Arabia. Journal of Special Education and Rehabilitation, 10(36), 1-40. doi:10.21608/SERO.2020.104313

Mills, G. E., \& Gay, L. R. (2019). Educational research: Competencies for analysis and applications. New Jersey 07458: Pearson. 
Mohr-Jensen, C., Steen-Jensen, T., Bang-Schnack, M., \& Thingvad, H. (2019). What Do Primary and Secondary School Teachers Know About ADHD in Children? Findings From a Systematic Review and a Representative, Nationwide Sample of Danish Teachers. Journal of attention disorders, 23(3), 206-219. doi:10.1177/1087054715599206

Obeidat, Y. F. (2014). The effectiveness of a training program in improving the level of knowledge of attention deficit disorder and hyperactivity among public education teachers in Jeddah city. Journal of Al-Quds Open University, 333(2305), 166.

Ouellet, M.-C., Beaulieu-Bonneau, S., Savard, J., \& Morin, C. M. (2019). Insomnia and Fatigue After Traumatic Brain Injury: A CBT Approach to Assessment and Treatment: Academic Press.

Pearson, S., Clarke, P., \& Chambers, M. (2014). Saudi Arabian Teachers' Knowledge and Beliefs about ADHD Mohaned Abed Program of Educational Graduate Studies, King Abdulaziz University, Kingdom of Saudi Arabia mabed@ kau. edu. sa. The Journal of the International Association of Special Education, 15(1), 67.

Pierangelo, R., \& Giuliani, G. (2015). Classroom Management Techniques for Students with ADHD: A Step-by-Step Guide for Educators. New York, NY: Skyhorse Publishing.

Poznanski, B., Hart, K. C., \& Cramer, E. (2018). Are Teachers Ready? Preservice Teacher Knowledge of Classroom Management and ADHD. School Mental Health, 10(3), 301-313. doi:10.1007/s12310-018-9259-2

Prinstein, M. J., Youngstrom, E. A., Mash, E. J., \& Barkley, R. A. (2019). Treatment of Disorders in Childhood and Adolescence (4 ed.). New York, NY: Guilford Publications.

Punja, S., Shamseer, L., Hartling, L., Urichuk, L., Vandermeer, B., Nikles, J., \& Vohra, S. (2016). Amphetamines for attention deficit hyperactivity disorder (ADHD) in children and adolescents. Cochrane Database of Systematic Reviews(2), 107. doi:10.1002/14651858.CD009996.pub2

Rief, S. F. (2016). How To Reach And Teach Children with ADD / ADHD: Practical Techniques, Strategies, and Interventions (3 ed.). USA: John Wiley \& Sons.

Rowland, A. S., Skipper, B. J., Umbach, D. M., Rabiner, D. L., Campbell, R. A., Naftel, A. J., \& Sandler, D. P. J. J. o. a. d. (2015). The prevalence of ADHD in a populationbased sample. Journal of attention disorders, 19(9), 741-754. doi:10.1177/1087054713513799

Sarraf, N., Karahmadi, M., Marasy, M. R., \& Azhar, S. M. M. (2011). A comparative study of the effectiveness of nonattendance and workshop education of primary school teachers on their knowledge, attitude and function towards ADHD students in Isfahan in 2010. Journal of research in medical sciences: the official journal of Isfahan University of Medical Sciences, 16(9), 1196-1201.

Sciutto, M. J., Terjesen, M. D., \& Frank, A. S. B. (2000). Teachers' knowledge and misperceptions of attention-deficit/hyperactivity disorder. Psychology in the Schools, 37(2), 115-122. doi:10.1002/(SICI)1520-6807(200003)37:2<115::AIDPITS3>3.0.CO;2-5

Shroff, H. P., Hardikar-Sawant, S., \& Prabhudesai, A. D. (2017). Knowledge and Misperceptions about Attention Deficit Hyperactivity Disorder (ADHD) Among School Teachers in Mumbai, India. International Journal of Disability, Development and Education, 64(5), 514-525. doi:10.1080/1034912X.2017.1296937

Soroa, M., Gorostiaga, A., \& Balluerka, N. (2013). Review of tools used for assessing teachers' level of knowledge with regards attention deficit hyperactivity disorder (ADHD). In S. Banerjee (Ed.), Attention deficit hyperactivity disorder in children and adolescents: IntechOpen. 
Storebø, O. J., Ramstad, E., Krogh, H. B., Nilausen, T. D., Skoog, M., Holmskov, M., . . Moreira-Maia, C. R. (2015). Methylphenidate for children and adolescents with attention deficit hyperactivity disorder (ADHD). Cochrane Database of Systematic Reviews(11). doi:10.1002/14651858.CD009885.pub2

Syed, E. U., \& Hussein, S. A. (2010). Increase in teachers' knowledge about ADHD after a week-long training program: A pilot study. Journal of attention disorders, 13(4), 420423. doi:10.1177/1087054708329972

Vasko, J. M., Oddo, L. E., Meinzer, M. C., Garner, A., \& Chronis-Tuscano, A. (2020). Psychosocial Interventions for College Students with ADHD: Current Status and Future Directions. The ADHD Report, 28(4), 5-12, 14. doi:10.1521/adhd.2020.28.4.5

Yarde-Leavett, C. (2018). Teachers' knowledge of and attitudes towards ADHD in the Western Cape. (Master's Thesis), University of Cape Town South African Retrieved from http://www.psychology.uct.ac.za/sites/default/files/image_tool/images/117 /Logos/thesis/Claire\%20Yarde-Leavett\%20Thesis\%202018\%20.pdf 